\title{
Education level impact on cardiometabolic risk factors: a brief report
}

\author{
Rinat Khalifah-Ourfali ${ }^{1}$, Rebeca Kababie-Ameo ${ }^{1}$, Eduardo Meaney ${ }^{2}$, Guillermo Ceballos ${ }^{2 *}$ and Gabriela Gutiérrez-Salmeán ${ }^{1,2 * *}$ \\ ${ }^{1}$ Facultad de Ciencias de la Salud, Universidad Anáhuac México Norte, Mexico \\ ${ }^{2}$ Laboratorio de Investigación Integral Cardiometabólica, Sección de Estudios de Posgrado e Investigación de la, Escuela Superior de Medicina del Instituto Poli- \\ técnico Nacional, Mexico \\ "Co-senior this work
}

\begin{abstract}
Objective: To determine the association between education level and cardiometabolic risk factors in Mexican adults.

Design: Case-control study.

Setting and participants: Previously recollected database.

Main measures: Overweight or obesity, hypertension (SAH), hyperglycemia, and hypercholesterolemia were considered as cardiometabolic risk factors. These were further associated with education levels: low, basic, middle, and superior.

Analysis: Descriptive statistics, chi-square tests with subsequent odds ratio calculation for each cardiometabolic abnormality, considering the basic education level as reference (i.e., $\mathrm{OR}=1$ ).

Results: Prevalence for overweight and obesity was $\approx 70 \%$, hypertension $28.1 \%$, hypercholesterolemia $18.2 \%$, and hyperglycemia $9.4 \%$. SAH and hyperglycemia were inversely associated with educational level, whilst hypercholesterolemia presented the same trend up to high education but then increased when reaching a superior education level. Obesity was less prevalent in more educated subjects; but no clear-cut trend was identified for overweight. Odds ratio showed that low educational level doubles the risk of presenting all cardiometabolic abnormalities; with the exception of hypercholesterolemia.
\end{abstract}

Conclusions and implications: Education level plays an important role in the presence of cardiometabolic risks, therefore it is mandatory to extend health-education policies nationwide.

\section{Background and objective}

In Mexico, the education system scheme is divided in three broad categories: basic (preescolar, primaria (elementary), secundaria (junior high)), mid-superior (profesional técnico (technical), preparatoria (high school)), and superior (licenciatura (college), posgrado (posgraduated)) levels. Although in 2012, almost 35 million students were enrolled nationwide, completion rates (i.e., terminal efficiency) dramatically decrease as education grades increase thus, just 24 out of 100 children who started basic education level, complete the mid superior stage; and only 13 of them get the academic superior degree [1]. Finally, barely 16 of every 10,000 Mexicans undergo graduate school.

Recent national surveys have reported a combined prevalence of $\approx 70 \%$ of adult overweight and obesity. Such abnormal nutritional statuses are major determinants for the development of diabetes mellitus (DM), systemic arterial hypertension (SAH) and cardiovascular disease. Although these cardiometabolic ailments, according to the World Health Organization (WHO), are associated to $\approx 30 \%$ of the worldwide deaths, the obesity-related epidemics has affected certain social groups more than others; particularly those with a lower level of education [2].

Although the association between education level and overweight/ obesity and its associated cardiometabolic consequences has been widely described [3,4], their cause-effect link is rather complex, hence the full understanding of the nature of the precise mechanisms affecting health are yet obscure. In this matter, several studies have found strong associations among social factors (amidst them, education) and the development of such diseases $[5,6]$. Cohort studies have reported an inverse relationship between the social gradient (term implying that the lower socioeconomic and education strata of a society is associated, at the same time, with the worst health conditions) and the prevalence of metabolic syndrome (MS). Moreover, subjects with lowgrade education, exhibit a three-fold increase in mortality rates when compared to those with higher educational grades [6-10]. As example, Andreenko et al demonstrated that men with university education have lower mean values of body mass index (BMI) than men with just primary and secondary education [11].

As previously mentioned, these phenomena have not been fully elucidated, but some studies have reported that the higher the education

Correspondence to: Gabriela Gutiérrez-Salmeán, PhD, Facultad de Ciencias de la Salud, Universidad Anáhuac México Norte, Av. Universidad Anáhuac \#46. Lomas Anáhuac, Huixquilucan, Estado de México, México, Tel: 525556270210; E-mail: gabrielasalmean@yahoo.com

Key words: cardiometabolic risk factors, education, hypercholesterolemia, hyperglycemia, hypertension, obesity, overweight

Received: June 05, 2017; Accepted: July 07, 2017; Published: July 10, 2017 
level, the more probability of adequate nutrition -and hence, less chance for presenting obesity and its comorbidities- due to the fact that these individuals are often more aware of the importance of nutritional habits and the practice of regular exercise $[5,6]$. On this regard, it has been established [12-14] that those with more years of education are less likely to smoke, drink heavily, or to be overweighed or obese. Similarly, the better educated subjects are more likely to exercise and use preventive care procedures such as vaccines, mammograms, Papanicolau tests and colonoscopies.

Due to the aforementioned, the objective of the present study were to determine the association between education level and the risk of presenting cardiometabolic risk factors such as overweight/obesity, $\mathrm{SAH}$, hyperglycemia, and hypercholesterolemia in otherwise healthy Mexican adults.

\section{Setting, participants, and main measurements}

The study protocol was approved by institutional ethics and research committees. Individuals signed an informed consent. We conducted a case-control study in. a non-probabilistic sample comprised of 300,000 individuals. The sample population was obtained by the surveying of consenting individuals of any gender, aged 18 years or more, recruited in public sites in six of the more populated cities in Mexico, two of them in Northern Mexico (Monterrey and Tijuana), one in the Occidental region (Guadalajara), and three in Central Mexico (Mexico City, Puebla and León).

BMI was calculated from the reported height $(\mathrm{m})$ and weight $(\mathrm{kg})$ and was further classified into normal $\left(<25 \mathrm{Kg} / \mathrm{m}^{2}\right)$, overweight $(>25$ $\left.29.9 \mathrm{~kg} / \mathrm{m}^{2}\right)$ and obesity $\left(\geq 30 \mathrm{~kg} / \mathrm{m}^{2}\right)$.

Blood pressure (BP) was measured following international recommendations. SAH was considered with systolic blood pressure $\geq 140$ and/or diastolic blood pressure $\geq 90 \mathrm{mmHg}$ ).

We measured glucose (with at least $5 \mathrm{~h}$ of fasting) in capillary blood using an Accutrends ${ }^{\circledR}$ apparatus. Fasting blood glucose was considered abnormal with values $>100 \mathrm{mg} / \mathrm{dL}$. Total cholesterol was measured also with an Accutrends apparatus and a total cholesterol level $>240 \mathrm{mg} / \mathrm{dL}$ determined the presence of hypercholesterolemia.

Four levels of education were considered: low (total illiteracy or basic reading/writing but with no formal elementary education), basic (either complete elementary or middle school), middle (high school), and superior education (college or more).

Further, data was separated by gender.

Statistical analysis. Descriptive statistics yielded overall and intragroupal frequencies. Chi-square test were then performed with subsequent odds ratio (OR) calculation for each cardiometabolic abnormality (e.g., hyperglycemia), considering the basic education level as reference (i.e., $\mathrm{OR}=1$ ).

Prism GraphPad (GraphPad, San Diego, CA, USA) was used as statistical software and a $p$-value $<0.05$ was considered as significant.

\section{Results}

Overall, we found a combined prevalence for overweight and obesity $\approx 70 \%$ ( $41.6 \%$ and $27.5 \%$, respectively). SAH was found in $28.1 \%$ of the subjects, whilst hypercholesterolemia in $18.2 \%$, and hyperglycemia, in $9.4 \%$ of the studied population. Table 1 details the corresponding values according to gender.
Analysis according to educational level, as shown in Figure 1, clearly demonstrates that the frequency of SAH and hyperglycemia are inversely associated with educational level. Interestingly, hypercholesterolemia presented the same trend up to high education but then increased when reaching a superior education level.

\section{A Systemic Arterial Hypertension}

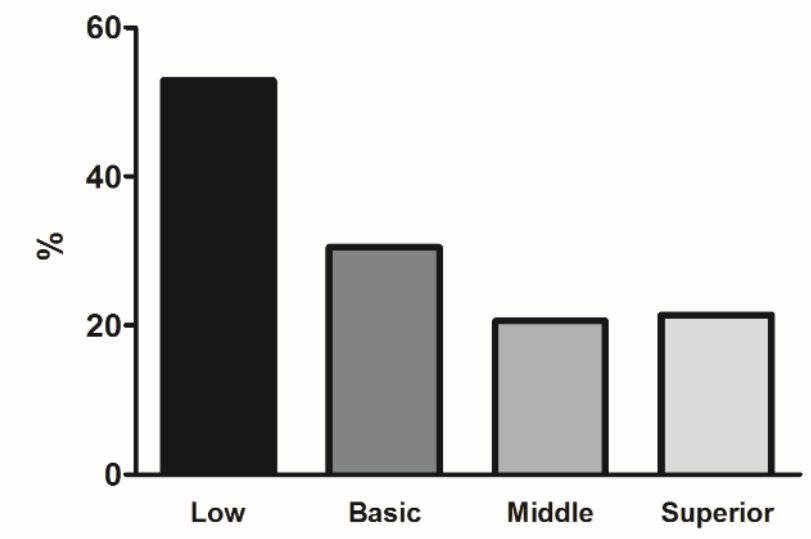

B

\section{Hyperglycemia}
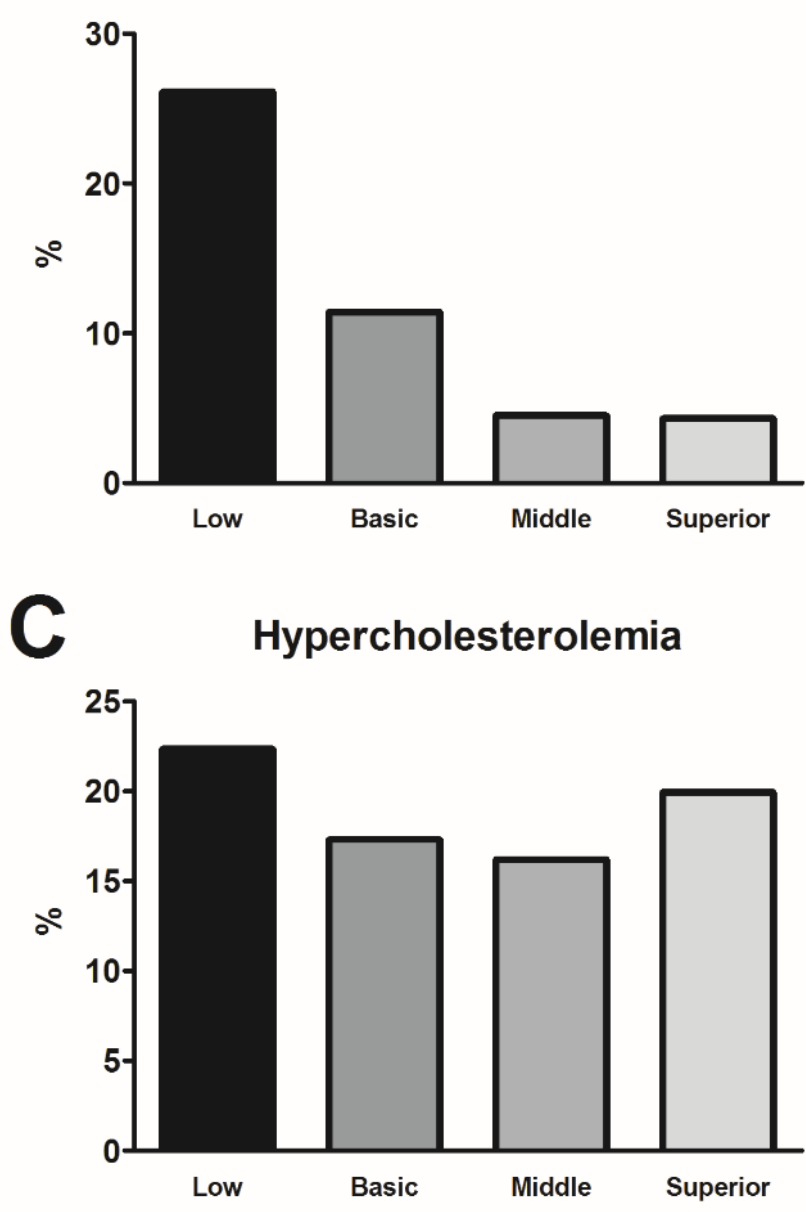

Figure 1. Overall frequencies of cardiometabolic risk factors according to educational level 
Regarding BMI status, the analysis (Figure 2) shows that the prevalence of obesity was lower among the more educated subjects; but in terms of overweight, there appears that there is no clearcut trend as all educational levels presented, essentially, the same frequency. Moreover, regression analysis revealed that as education level increases, the proportion of subjects with a normal BMI does so $\left(\mathrm{r}^{2}=0.9836, p<0.05\right)$; whilst a significant and equally strong inverse correlation $\left(\mathrm{r}^{2}=0.9771, p<0.05\right)$ was found between education level and the frequency of obesity.

Chi square-tests for association between cardiometabolic risk factors yielded a $p<0.05$, hence OR values were calculated. In brief, Table 2 shows that a low educational level significantly increases the risk -more than 2-fold- of presenting all cardiometabolic abnormalities (irrespectively of gender) and, moreover, such risk is attenuated with higher education. The exception was hypercholesterolemia, in which superior education showed an increased risk, although interestingly, this was only seen in men, but not among women.

\section{Discussion}

The proportions herein found were similar to those revealed in the National Survey on Health and Nutrition (ENSANUT, 2012), i.e., $\approx 70 \%$ of overweight and obesity, $9 \%$ of previously diagnosed diabetes, and $\approx 30 \%$ of SAH. However, the prevalence of hypercholesterolemia in this study was significantly higher than the reported in the ENSANUT $(\approx 12 \%)$ [15]. This finding may be explained by the fact our sample was predominantly urban. It has been extensively documented that the prevalence of hypercholesterolemia is higher among urban than rural populations, phenomenon that may be partially explained by lifestyle differences, including characteristic dietary patterns of urban life such as higher consumption of saturated and trans fatty acids, both of which are known to increase blood cholesterol level $[16,17]$.

But more importantly, the above-presented results show that education plays a determining role in cardiometabolic risk. In this regard, several rationalizations may be considered. It has been

Table 1. Frequency of cardiometabolic risk factors

\begin{tabular}{|c|c|c|c|}
\hline & Total n (\%) & Men n (\%) & Women n (\%) \\
\hline BMI (normal) & $94859(30.9)$ & $40121(13.06)$ & $54738(17.829$ \\
\hline BMI (overweight) & $127669(41.6)$ & $67040(21.83)$ & $60629(19.74)$ \\
\hline BMI (obesity) & $84529(27.5)$ & $34089(11.10)$ & $50440(16.42)$ \\
\hline Hypercholesterolemia & $55733(18.2)$ & $24316(7.91)$ & $31417(10.23)$ \\
\hline Hyperglycemia & $28983(9.4)$ & $11243(3.66)$ & $17740(5.77)$ \\
\hline SAH & $86196(28.1)$ & $37072(12.07)$ & $49124(15.99)$ \\
\hline
\end{tabular}

$\mathrm{N}=307060$ subjects; BMI: Body mass index; $\mathrm{SAH}$ : Systemic arterial hypertension

Table 2. ORs comparing level of education on its impact for cardiometabolic risk factors

\begin{tabular}{|c|c|c|c|c|}
\hline \multirow{2}{*}{ SAH } & Level & Total & Men & Women \\
\hline \multirow{3}{*}{ Hypercholesterolemia } & Low & 2.63 & 2.37 & 2.49 \\
\cline { 2 - 5 } & Middle & 0.62 & 0.79 & 0.59 \\
\cline { 2 - 5 } & Superior & 0.62 & 0.86 & 0.44 \\
\hline \multirow{3}{*}{ BMI (obesity) } & Low & 1.38 & 1.16 & 1.35 \\
\cline { 2 - 5 } & Middle & 0.93 & 1 & 0.87 \\
\cline { 2 - 5 } & Superior & 1.22 & 1.6 & 1.00 \\
\hline \multirow{3}{*}{ Hyperglycemia } & Low & 1.36 & 1.11 & 1.29 \\
\cline { 2 - 5 } & Middle & 0.63 & 0.85 & 0.53 \\
\cline { 2 - 5 } & Superior & 0.5 & 0.76 & 0.52 \\
\hline & Low & 2.84 & 2.71 & 2.84 \\
\cline { 2 - 5 } & Middle & 0.43 & 0.31 & 0.47 \\
\cline { 2 - 5 } & Superior & 0.39 & 0.23 & 0.47 \\
\hline
\end{tabular}

Basic educational level was considered as the reference group thus $\mathrm{OR}=1$ proposed that people who have little or no education are not well aware about the importance of healthy eating (e.g., they cannot read public health campaigns or have deficient information about the components of a healthy diet), or have less access to fitter food (e.g., they cannot read or clearly understand labels and therefore are not able to make an informed decision on what to eat) [18-20]. Complementary, subjects with high education level are considered to achieve a better understanding of the impact of diet in cardiometabolic risk and overall health, hence exhibit healthier eating patterns [21,22]. But the more important issue in this regard is the fact that low education is -almost always- associated with lower income, and "eating healthily" now costs three times as much as 10 years ago; hence, this may also contribute to the fact that low education/income grades persistently show higher morbidity rates.

As a document published by the WHO states, one of the main social factors that contribute to the development of $\mathrm{SAH}$, hypercholesterolemia and its complications, is low level of education combined with an unhealthy diet, both associated with low incomes [23,24].

Finally, the ORs at the superior level of education should theoretically be the lowest but, unexpectedly, trends showed that the prevalence of risk factors is either equal $(\approx)$ or higher than that on the preceding education stratum. This phenomenon may imply that the fact that a person "can read", does not necessarily mean that he/ she is "well informed" about the cardiometabolic consequences of overweight and obesity or, worse, they simply do not care or are not willing to make therapeutic lifestyle changes.-

The individual development of a preventive consciousness is the consequence of many personal and social intertwined factors. It is supposed that a higher level of education allows a wider and deeper comprehension of heath and disease, thus making easy the adoption of healthier lifestyles. But this is not entirely true in all cases. One thing is the knowledge and information, and other the introjection of those learnings and its conversion in specific positive behavioral acts. Many very well-informed individuals, including physicians and researchers do not adopt on purpose a healthy life, for rather complicate mental processes. Therefore, alongside with raising the general educational level of a society, and incorporating since the elementary school, the concepts and foundations of medical prevention, it is mandatory that the state (not only the executive branch, but the legislative and judiciary chambers as well) could enact strong public policies addressed to promote a healthy nutrition, the adoption of physical exercise and tobacco restriction. The state public actions in this regard encompass specific legislation, rewarding or punishing tax strategies, powerful and long-lasting campaigns in mass media and setting up compromises with the alimentary industry to market healthier products with fewer allowable contaminants, less calories from sweeteners, saturated, trans fat and lower salt content.

\section{Conclusion}

The results of this study show that education plays an important role in cardiometabolic risk development or status. The correlation between education and health may reflect three possible types of relationships: a) a causal link running from increased education to improved health, b) a reverse causal link, indicating that better health leads to greater education; or c) an absence of a causal relationship between education and health, which appear to be correlated because of possible unobserved factors affecting both health (or obesity) and education in the same direction. The three pathways are not mutually exclusive, of course, and some combination of the three is likely to provide the most 

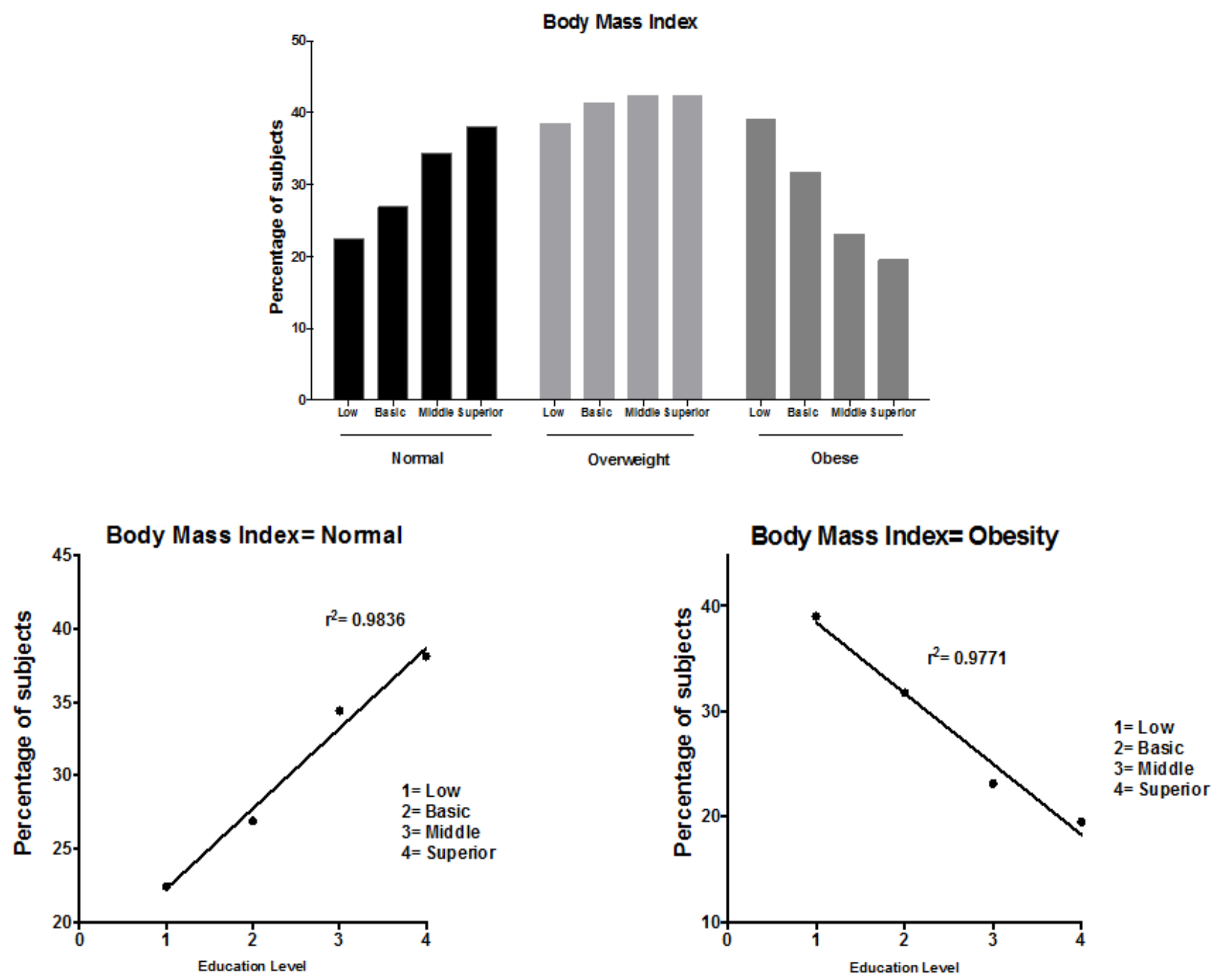

Figure 2. Frequencies and regression analysis of BMI status according to educational level

plausible explanation of the strong correlations consistently found across countries between education and health, or obesity.

\section{Implications for research and practice}

As it is herein shown, education level plays an important role regarding the presence of cardiometabolic risk factors. Although its participation is rather complex, governmental projects and policies ought to be developed and applied nationwide in aims of containingideally, reversing- the current epidemic of obesity and its associated comorbidities.

\section{References}

1. López EG, Lázaro IG (2010) Aprendizaje basado en la resolución de problemas: una experiencia práctica. Educ Médica 13: 15-24.

2. No authors listed (2003) Diet, nutrition and the prevention of chronic diseases. World Health Organ Tech Rep Ser 916: i-viii, 1-149, backcover. [Crossref]

3. Laraia B, Karter AJ, Warton EM, Schillinger D, Moffet HH, et al. (2012) Place matters: neighborhood deprivation and cardiometabolic risk factors in the Diabetes Study of Northern California (DISTANCE). Soc Sci Med 74(7): 1082-1090. [Crossref]

4. Després JP, Lemieux I, Bergeron J, Pibarot P, Mathieu P, et al. (2008) Abdominal obesity and the metabolic syndrome: contribution to global cardiometabolic risk. Arterioscler Thromb Vasc Biol 28(6): 1039-1049. [Crossref]
5. Isomaa B, Almgren P, Tuomi T, Forsén B, Lahti K, et al. (2001) Cardiovascular morbidity and mortality associated with the metabolic syndrome. Diabetes Care 24(4): 683-689. [Crossref]

6. Malik S, Wong ND, Franklin SS, Kamath TV, L'Italien GJ, et al. (2004) Impact of the metabolic syndrome on mortality from coronary heart disease, cardiovascular disease, and all causes in United States adults. Circulation 110: 1245-1250. [Crossref]

7. Ouviña SM, Sassetti B (2006) Plasmatic fibrinogen, its relationship with weight, lipids, and smoking in healthy individuals. Acta Bioquímica Clinica Latinoam 40(4): 469-472.

8. Jamison EA, Jamison DT, Hanushek EA (2007) The effects of education quality on income growth and mortality decline. Econ Educ Rev 26(6): 771-788.

9. Lleras-Muney A (2005) The relationship between education and adult mortality in the United States. Rev Econ Stud 72(1): 189-221.

10. Pereira A, Guedes AD, Verreschi ITN, Santos RD, Martinez TL, et al. (2009) Obesity and its association with other cardiovascular risk factors in school children in Itapetininga, Brazil. Arq Bras Cardiol 93(3): 253-260. [Crossref]

11. Andreenko E, Mladenova S, Akabaliev V (2015) Anthropometric obesity indices in relation to age, educational level, occupation and physical activity in Bulgarian men. Nutr Hosp 31(2): 658-665. [Crossref]

12. de Walque D (2007) Does education affect smoking behaviors? Evidence using the Vietnam draft as an instrument for college education. J Health Econ 26(5): 877-895. [Crossref]

13. Finkelstein EA, Ruhm CJ, Kosa KM (2005) Economic causes and consequences of obesity. Annu Rev Public Health 26: 239-257. [Crossref] 
14. Lê F, Ahern J, Galea S (2010) Neighborhood education inequality and drinking behavior. Drug Alcohol Depend 112(1-2): 18-26. [Crossref]

15. Instituto Nacional de Salud Pública (2012) Encuesta Nacional de Salud y Nutrición 2012. Resultados Nacionales. ENSANUT 2012: 1-200.

16. Riccardi G, Giacco R, Rivellese AA (2004) Dietary fat, insulin sensitivity and the metabolic syndrome. Clin Nutr 23: 447-456. [Crossref]

17. Lottenberg AM, Afonso Mda S, Lavrador MS, Machado RM, Nakandakare ER (2012) The role of dietary fatty acids in the pathology of metabolic syndrome. J Nutr Biochem 23: 1027-1040. [Crossref]

18. Laaksonen DE (2002) Metabolic syndrome and development of diabetes mellitus: application and validation of recently suggested definitions of the metabolic syndrome in a prospective cohort study. Am J Epidemiol 156(11): 1070-1077. [Crossref]

19. Poirier P, Giles TD, Bray G, Hong Y, Stern JS, et al. (2006) Obesity and cardiovascular disease: pathophysiology, evaluation, and effect of weight loss. Arterioscler Thromb Vasc Biol 26(5): 968-976. [Crossref]
20. Gutiérrez-Salmeán G, Meaney A, Ocharán ME, Araujo JM, Ramírez-Sánchez I, et al (2013) Anthropometric traits, blood pressure, and dietary and physical exercise habits in health sciences students; the obesity observatory project. Nutr Hosp 28(1): 194-201. [Crossref]

21. Satter E (2007) Eating Competence: Nutrition education with the satter eating competence model. J Nutr Educ Behav 39: S189-S194. [Crossref]

22. Yahia N, Achkar A, Abdallah A, Rizk S (2008) Eating habits and obesity among Lebanese university students. Nutr J 7: 32. [Crossref]

23. Magee MJ, Narayan KM (2013) Global confluence of infectious and non-communicable diseases -- the case of type 2 diabetes. Prev Med 57: 149-151. [Crossref]

24. Dye C, Mertens T, Hirnschall G, Mpanju-Shumbusho W, Newman RD, et al. (2013) WHO and the future of disease control programmes. Lancet 381(9864): 413-418. [Crossref]

Copyright: (C2017 Gutiérrez-Salmeán G. This is an open-access article distributed under the terms of the Creative Commons Attribution License, which permits unrestricted use, distribution, and reproduction in any medium, provided the original author and source are credited. 